\title{
Miniaturized multi-sensor loggers provide new insight into year-round flight behaviour of small trans-Sahara avian migrants
}

Felix Liechti ${ }^{*}$ D , Silke Bauer ${ }^{1}$, Kiran L. Dhanjal-Adams ${ }^{1}$, Tamara Emmenegger ${ }^{1}$, Pavel Zehtindjiev² and Steffen Hahn ${ }^{1}$

\begin{abstract}
Background: Over the past decade, the miniaturisation of animal borne tags such as geolocators and GPS-transmitters has revolutionized our knowledge of the whereabouts of migratory species. Novel light-weight multi-sensor loggers (1.4 g), which harbour sensors for measuring ambient light intensity, atmospheric pressure, temperature and acceleration, were fixed to two long-distance migrant bird species - eurasian hoopoe (Upupa epops) and great reed warbler (Acrocephalus arundinaceus). Using acceleration and atmospheric pressure data recorded every 5 and 30 min, respectively, we aimed at reconstructing individual diurnal and seasonal patterns of flight activity and flight altitude and thereby, at describing basic, yet hitherto unknown characteristics of migratory flight behaviour. Furthermore, we wanted to characterise the variability in these migration characteristics between individuals, species and migration periods.

Results: The flight duration from breeding to sub-Saharan African non-breeding sites and back was more variable within than between the species. Great reed warblers were airborne for a total of 252 flight hours and thus, only slightly longer than eurasian hoopoes with $232 \mathrm{~h}$. With a few exceptions, both species migrated predominantly nocturnally - departure around dusk and landing before dawn. Mean flight altitudes were higher during pre- than during post-breeding migration (median 1100 to $1600 \mathrm{~m}$ a.s.l.) and flight above $3000 \mathrm{~m}$ occurred regularly with a few great reed warblers exceeding $6000 \mathrm{~m}$ a.s.l. (max. $6458 \mathrm{~m}$ a.s.l.). Individuals changed flight altitudes repeatedly during a flight bout, indicating a continuous search for (more) favourable flight conditions.

Conclusions: We found high variation between individuals in the flight behaviour parameters measured - a variation that surprisingly even exceeded the variation between the species. More importantly, our results have shown that multi-sensor loggers have the potential to provide detailed insights into many fundamental aspects of individual behaviour in small aerial migrants. Combining the data recorded on the multiple sensors with, e.g., remote sensing data like weather and habitat quality on the spatial and temporal scale will be a great step forward to explore individual decisions during migration and their consequences.
\end{abstract}

Keywords: Biologging, Migration, Flight, Timing, Altitude, Activity, Eurasian hoopoe, Great reed warbler

\footnotetext{
* Correspondence: felix.liechti@vogelwarte.ch

'Swiss Ornithological Institute, Department of Bird Migration, Seerose 1, 6204

Sempach, Switzerland

Full list of author information is available at the end of the article
}

(c) The Author(s). 2018 Open Access This article is distributed under the terms of the Creative Commons Attribution 4.0 International License (http://creativecommons.org/licenses/by/4.0/), which permits unrestricted use, distribution, and reproduction in any medium, provided you give appropriate credit to the original author(s) and the source, provide a link to the Creative Commons license, and indicate if changes were made. The Creative Commons Public Domain Dedication waiver (http://creativecommons.org/publicdomain/zero/1.0/) applies to the data made available in this article, unless otherwise stated. 


\section{Background}

Over the past decade, the miniaturisation of animal borne tags such as geolocators and GPS-transmitters has revolutionized our knowledge of the whereabouts of migratory species. Although we now know where and when many bird species migrate, we still know very little about their behaviour during migration. For instance, important characteristics like how often they engage in sustained flights or land to stop-over, whether they exclusively migrate during day or night, and which heights they choose for migratory flights, are still hardly known.

Knowing the year-round movement patterns is a prerequisite for investigating individual life cycles [1]. To study year-round energy expenditure, individual behaviour in relation to environmental conditions, or carry over effects, not only requires knowledge on where an individual is, but also on how and when it is being active and moves between different locations. Especially in migratory birds, movement patterns are key factors of the annual cycle. In recent years, large birds like seabirds and raptors have been equipped with tags that allow positioning with high resolution (e.g. [2, 3], but also monitor flight altitudes and even behavioural aspects by acceleration sensors [4]. However, the overall weight of these tags has limited their applicability to birds weighing more than $100 \mathrm{~g}$. With the development of miniaturized light-level geolocators [5], the number of studies tracking small passerines and near-passerines has greatly increased (e.g. [6-13]. Light-level geolocators allow the estimation of movement and stationary periods along the annual cycle [14], but provide no insight into the actual flight behaviour.

To date, information on the behaviour of free flying individual small birds, like flight altitude, diurnal pattern of flight time or flight speed and flight direction was only available from radar tracking (e.g. [15-27] and telemetry studies (e.g. [28-31]. With radar, however, species identification is rarely possible and behavioural data can only be collected over short distances (in the best case a few tens of kilometres), with virtually nothing else being known about the tracked individual. Telemetry recordings have been performed by following single birds by plane for several hours or by a network of fixed ground base stations, providing the temporal pattern of passage for a specific area - but again, this only provides information on behaviour over short spatial and temporal scales.

Newly developed miniaturized multi-sensor loggers monitor light for geolocation, and simultaneously record acceleration and air pressure [32]. Analysing acceleration and air pressure at temporal resolutions of minutes sheds light on many aspects of individual behaviour throughout the year - such as daily patterns of categorized behaviour like flying, foraging and resting, and altitudes during flight. The aim of this study is to reveal basic but hitherto unknown migration characteristics in two trans-Saharan migrants, the great reed warbler (Acrocephalus arundinaceus) and the eurasian hoopoe (Upupa epops), to illustrate the potential of these new devices. We explore and compare characteristics of migratory behavior of the two species, e.g. it is still discussed whether the eurosiann hoopoe is diurnal or nocturnal migrant [33, 34], while the great reed warbler is generally considered to migrate a night. According to the morphological differences between the two species, we hypothesize that great reed warblers would travel more efficiently than hoopoes, which might be disadvantaged by their broad wings resulting in the well-known fickle flight style. Wing-loading is about $60 \%$ higher in the warbler compared to the hoopoe, whereas the aspect ratio of the wing (narrowness) is about $30 \%$ higher in the warbler [35]. Higher wing loading is related to higher airspeeds in birds [21], whereas low wing loadings and broad wings produce more lift. Therefore, we expect great reed warbles to fly faster and having longer flight bouts than hoopoes resulting in higher migration speeds, whereas hoopoes would expect to have higher climb rates. In particular, we compare the seasonal pattern of flight bouts, diurnal take-off and landing times, mean and maximum flight altitudes and rates of climb of the two species.

\section{Methods}

\section{Species and study sites}

The eurasian hoopoe is a medium-sized bird, 25-32 cm long, with a 44-48 cm wingspan and a body mass of 46-89 g [33]. We applied 19 multi-sensor loggers (GDL3-PAM) on adult breeders from a population that has been studied since 15 years [36, 37]. The study site is located in an inner-alpine valley in south-western Switzerland $\left(46^{\circ} 14^{\prime} \mathrm{N} 7^{\circ} 22^{\prime} \mathrm{E}\right)$.

The great reed warbler measures about $16-21 \mathrm{~cm}$ in length, 25-30 cm in wingspan and weighs 22-38 g [38]. The study was done in Biological Station Kalimok (Institute of Biodiversity and Ecosystem Research at Bulgarian Academy of Sciences) located in north-eastern Bulgaria $\left(44^{\circ} 00^{\prime} \mathrm{N}, 26^{\circ} 26^{\prime} \mathrm{E}\right)$. We equipped 70 adults with the multi-sensor loggers. Studies on this population have taken place since 2005 [39, 40]. The study site is situated in reed beds of a former fish pond area associated with the Danube river.

Both, eurasian hoopoes and great reed warblers are long-distance migrants that migrate from their European breeding grounds to the western Sahel region $[6,41]$ and to central and eastern Africa [42, 43], respectively. Both species are well known to use flapping flight with no indication of soaring flight [15]. Thus, they are well suited for a comparative study of flight behaviour using accelerometers. 


\section{Multi-sensor loggers}

The multi-sensor loggers (i.e. GDL3-PAM) were developed and produced by the Swiss Ornithological institute in cooperation with the Bern University of Applied Sciences. The loggers consist of sensors for measuring ambient light intensity, air pressure, acceleration, temperature and magnetic field. The average weight of a logger in our study was $1.4 \mathrm{~g}$ (range 1.3-1.45 g) including battery, coating and leg loop harness, corresponding to $2.2 \%$ of mean body mass for a hoopoe and $4.5 \%$ for a great reed warbler. Former studies have shown no deleterious effects of the loggers on return rate and reproductive success for hoopoes [44]. Recapture rate of eurasian hoopoes was $26 \%$ (5 of 19) for the birds equipped with loggers compared to $18 \%$ (12 of 65 ) for the control group (ringed only birds). Recapture rates of great reed warblers equipped with loggers was $20 \%$ (14 of 70 ), compared to $13 \%$ of the controls (5 of 38). One of the great reed warblers equipped with a logger returned without a logger.

Recording intervals of GDL3-PAM loggers can be customized in accordance to a particular study focus. As we aimed for a year-round monitoring of behaviour and movements, while simultaneously optimising battery life and memory usage, we chose measurement intervals of $5 \mathrm{~min}$ for light intensity, $30 \mathrm{~min}$ for air pressure and temperature recordings and $5 \mathrm{~min}$ for acceleration.

\section{Activity measurements}

The accelerometer sensor recorded acceleration along the Z-axis every $5 \mathrm{~min}$ for $3.2 \mathrm{~s}$ with a frequency of $10 \mathrm{~Hz}$ [45]. An on-board algorithm calculated the mean of the 32 values representing the relative position of the body axis with respect to the horizontal plane (pitch), and the sum of the absolute differences between consecutive points (31 values) representing the relative activity (Additional file 1: Figure S1). Field tests with continuous acceleration data $(10 \mathrm{~Hz})$ had shown that by using these compressed data, flapping flight can be separated reliably from other activities [45].

Data on activity derived from accelerometry is suitable to determine phases of flight activity, because both species exclusively use flapping flight for migration (Fig. 1). We developed an automated algorithm to differentiate between three categories of behaviour (flight, other activities and resting). Resting was defined by an activity level of zero. For each individual tag we revealed the first local minimum from the frequency distribution of the activity recordings. This minimum was assigned as the threshold between flight and other activities (for details see Additional file 1: Figure S2). Finally, flight bouts were defined if at least three consecutive activity recordings were classified as flight, which corresponds to a (minimum) flight duration of 15 to $19 \mathrm{~min}$.

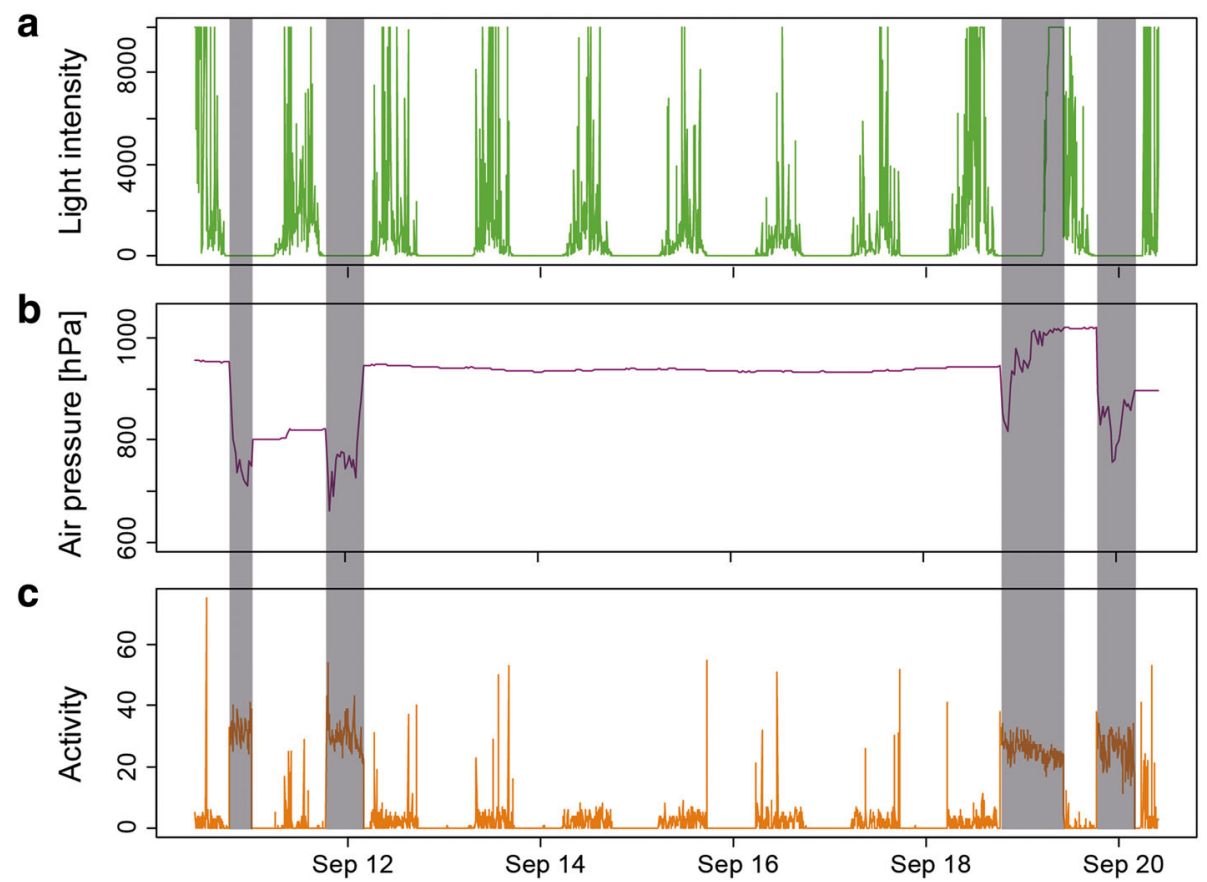

Fig. 1 Example of raw data time series of (a) light intensity (green), (b) air pressure (pink) and (c) activity (orange). Activity is derived from accelerometer data and processed on board (see methods). Examples of single flight bouts are marked by shaded areas. Y-scales for light and activity show arbitrary raw values as recorded by the sensors 


\section{Altitude measurements}

We used atmospheric pressure measurements to estimate altitudes above sea level based on the hypsometric equation [46], assuming standard atmospheric conditions (formula see Additional file 1). For reliability, we compared pressure measurements from the loggers to measurements from a local MeteoSwiss (Federal office of Meteorology and Climatology) weather station (distance $15 \mathrm{~km}, 12 \mathrm{~m}$ higher above sea level) than the logger site) for 3 days before loggers were deployed. Absolute differences ranged from -0.7 to $3.8 \mathrm{hPa}$ $(n=829)$. The mean difference of $1.5 \mathrm{hPa}$ corresponds very well to the $12 \mathrm{~m}$ height difference. Please note that flight altitudes derived from atmospheric pressure measurements alone, based on standardised atmospheric conditions, can deviate from real height by several tens of meters. Sea level pressure varies according to high and low pressure centres passing through an area but rarely resulting in height differences of more than $200 \mathrm{~m}(\sim 25 \mathrm{hPa})$. All flight altitudes given here correspond to height above sea level (a.s.l.).

The loggers of one eurasian hoopoe and two great reed warblers stopped recording during the pre-breeding (spring) migration period, and were therefore excluded from the overall and pre-breeding migration analyses.

\section{Data analyses}

Timestamps of all tags were linearly corrected for drift of the internal clocks. Clock-drift was less than $7 \mathrm{~min}$ for all, except one logger, which had a drift of $2 \mathrm{~h}$ over a period of 309 days. We assigned the times of flight based on the activity level (s. above) and determined the start and the end of single flight bouts for each individual. The proportion of nocturnal and diurnal flight activity was determined by referring to the light intensity data recorded in parallel. We calculated mean and maximum flight altitude for each flight bout. Based on the height difference between $30 \mathrm{~min}$ of flight we calculated climb rates, and the sum of all height gains across a flight bout (only positive climbs rates). Short-term changes in air pressure within 3-h are reported to be $1-2 \mathrm{hPa}$ ([47] $\mathrm{p}$. 117). Therefore, we expected errors in climb rate estimates due to changes in weather conditions to be insignificant. We used light intensity data to calculate geographic positions using SGAT (https://github.com/ SWotherspoon/SGAT), which is mainly based on threshold based positioning in GeoLight [48]. From the breeding sites and the median positions of the longest residency periods in Africa we calculated great circle distance as an estimate of minimum flight distances. For data processing and statistical analysis we used R-3.3.2 [49]. We applied a general linear mixed-effects model (R-package lme4) to test for differences between the two species and seasons with the individuals as a random factor.

\section{Results}

\section{Flight durations and distance}

The flight duration from breeding sites to sub-Saharan African non-breeding sites and back was more variable within than between the species. Great reed warblers needed between 212 to 369 flight hours, with the greatest differences in flight time between individuals was $75 \%$. In eurasian hoopoes, this difference between individuals was only $20 \%$ (Table 1 ). The median of overall flight time was slightly (8\%) smaller, whereas the average number of individual flight bouts was very similar with 45 and 47 flight bouts for great reed warblers and eurasian hoopoes, respectively. Overall, in great reed warblers the cummulative great circle distances between breeding grounds and non-breeding residence areas were $1300 \mathrm{~km}$ longer than in eurasian hoopoes (Table 1).

\section{Seasonal pattern of flight activity}

The flight activity over the year clearly revealed a seasonal pattern with peak activity during post- and pre-breeding migration in both species, but also show intra-tropical movement periods for most great reed warblers (Fig. 2). In hoopoes, flight times of post- compared to pre-breeding migration were very similar, while great reed warblers spent considerably more time flying during the pre-breeding migration than they did during both post-breeding migration and intra-tropical migration combined.

The temporal pattern of flight activities within the migration periods clearly differed between the species: Long stopovers prolonged the post-breeding migration of hoopoes from August into the end of October, whereas great reed warblers' flight activity was confined to in the second half of August only. Therefore, the overall duration of post-breeding migration was much shorter in great reed warblers than in hoopoes. To compare the main period of active migration between the species, we determined for each individual the time span that included $75 \%$ of the total flight hours per migration season. In hoopoes, the median for the post-breeding time period covered about three weeks, but only one week for great reed warblers (Fig. 3). For the pre-breeding migration, there was no difference between the two species (Figs. 2 and 3).

\section{Diurnal flight activity pattern}

Great reed warblers flew almost exclusively at night (median 97\%), whereas in eurasian hoopoes the proportion of nocturnal flights was slightly lower (median 88\%; Fig. 4). Departures for flights of $>4 \mathrm{~h}$ occurred exclusively in the evening, predominately around dusk (approx. Sun elevation - $3^{\circ}$ ), with $90 \%$ of the departures occurring between $1 \mathrm{~h}$ before and $2 \mathrm{~h}$ after 
Table 1 Overview of flight times and migratory distances per species and migration period. Distances given refer to the great circle route between the specific sites of residency along the annual cycle

\begin{tabular}{|c|c|c|c|c|c|c|}
\hline \multirow[t]{2}{*}{ Period } & \multirow[t]{2}{*}{ Species } & \multirow[t]{2}{*}{$N$} & \multicolumn{2}{|c|}{ Flight time [hour] } & \multicolumn{2}{|c|}{ Great circle distance [km] } \\
\hline & & & median & range & median & range \\
\hline \multirow[t]{2}{*}{ overall } & Great reed warbler & 11 & 252 & $212-319$ & 8886 & $7262-12,752$ \\
\hline & European hoopoe & 4 & 232 & $216-258$ & 7537 & $7101-8735$ \\
\hline \multirow[t]{2}{*}{ post-breeding $(<1.11 .15)$} & Great reed warbler & 13 & 82 & $63-133$ & 3998 & $3730-4557$ \\
\hline & European hoopoe & 5 & 115 & $71-133$ & 3769 & $3550-4367$ \\
\hline \multirow[t]{2}{*}{ intra-tropical (1.11.15 - 31.1.16) } & Great reed warbler & 13 & 25 & $3-65$ & 796 & $0-2256$ \\
\hline & European hoopoe & 5 & 0 & 0 & 0 & 0 \\
\hline \multirow[t]{2}{*}{ pre-breeding (> 31.1.16) } & Great reed warbler & 11 & 137 & $76-242$ & 4092 & $3532-5938$ \\
\hline & European hoopoe & 4 & 117 & $88-146$ & 3769 & $3550-4367$ \\
\hline
\end{tabular}

sunset (both species, Fig. 5, solid lines). Most birds landed before dawn, but landing could also occur during the day in both species. These prolonged flights into the day were more frequent in hoopoes $(7 \%>12 \mathrm{~h}$, maximum $28 \mathrm{~h})$ compared to great reed warblers $(4 \%>12 \mathrm{~h}$, maximum $22 \mathrm{~h})$. Short flights of less than $1 \mathrm{~h}$ occurring predominantly during migration periods (Fig. 2) were also more frequent in hoopoes $(30 \%)$ than in warblers $(19 \%)$. These short flights were initiated irrespective of day or night in hoopoes, while warbles preferred night time also for short flights (Fig. 5, dashed lines).

\section{Flight altitudes}

Median flight altitude during post-breeding migration was about $1150 \mathrm{~m}$ a.s.l. in both species, and around $1630 \mathrm{~m}$ a.s.l. during pre-breeding migration (Additional file 1: Table S1 and Figure S4). All individuals of both species flew at least once above $3000 \mathrm{~m}$ a.s.l., and in both species maximum flight altitudes per flight bout were slightly higher during pre-breeding compared to post-breeding migration. Nine out of 13 great reed warblers flew above $5000 \mathrm{~m}$, and 3 of them occasionally even above $6000 \mathrm{~m}$ (a.s.l.). Maximum altitude recorded for a great reed warbler was $6458 \mathrm{~m}$ a.s.l., and
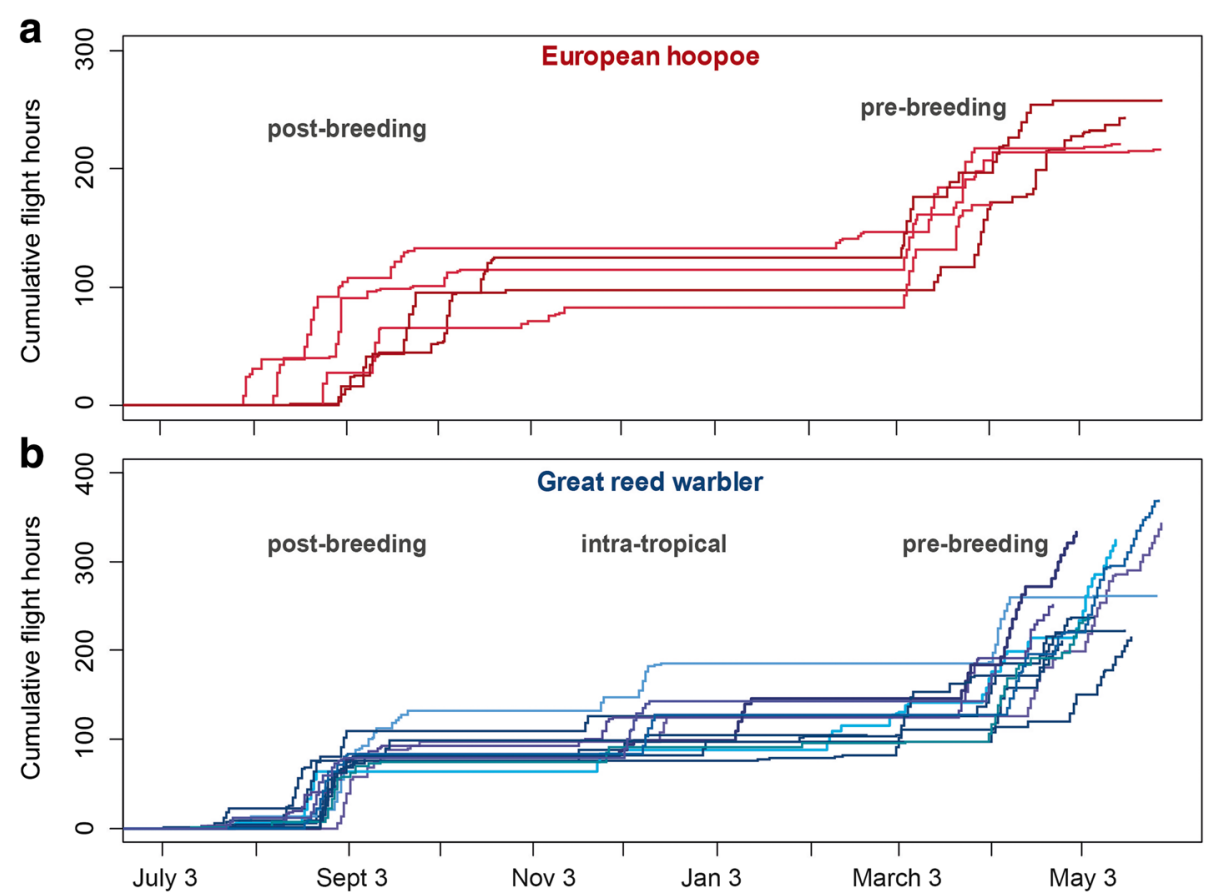

Fig. 2 Cumulative hours of flight of eurasian hoopoe $(N=5)$ and great reed wabler $(N=13)$ from July 2015 until April 2016. (a) Seasonal activity periods coincide with post- and pre-breeding migration in the hoopoe, while (b) reed warblers have an additional activity phase marked as intra-tropical movements 


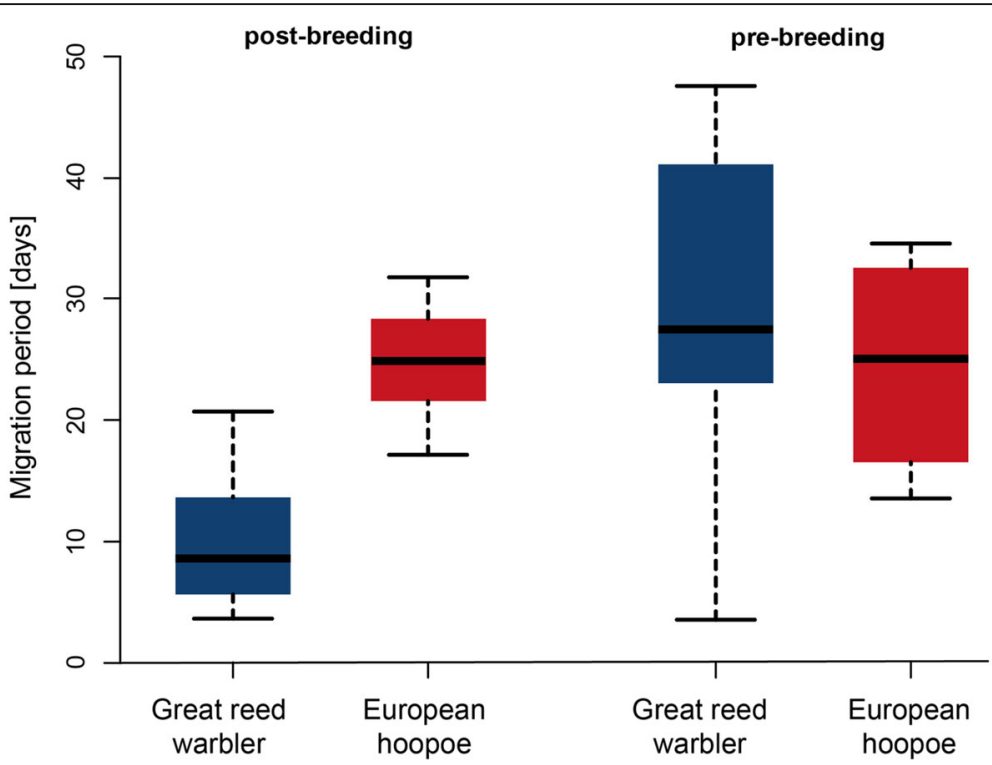

Fig. 3 Main period of post- and pre-breeding migration for great reed warbler and eurasian Hoopoe. Shown are the distributions of the shortest time period per individual including $75 \%$ of the flight time per migration season. The plots represent median, 50\% quantile and range

$4584 \mathrm{~m}$ a.s.l. for a European hoopoe (Fig. 6). There was a significant difference in mean and maximum flight altitudes between pre- and post-breeding migration (GLM for the mean heights, estimate $=406.7 \pm 76.6$, $\mathrm{t}$ value $=5.3$; maximum heights, $460.9 \pm 117.6$, $t$ value $=3.9)$, but not between the two species (GLM for the mean heights, $94.2 \pm$ 102.4, 0.9; maximum heights, $71.7 \pm 168.3,0.4$ ).

There was a significant relationship of decreasing climb rates with increasing flight duration $\left(X^{2}=221.3\right.$, $p<0.0001, N=4739$ ), which mainly resulted from high climb rates occurring more frequently within the first hour after departure (Fig. 7a). Apart from this

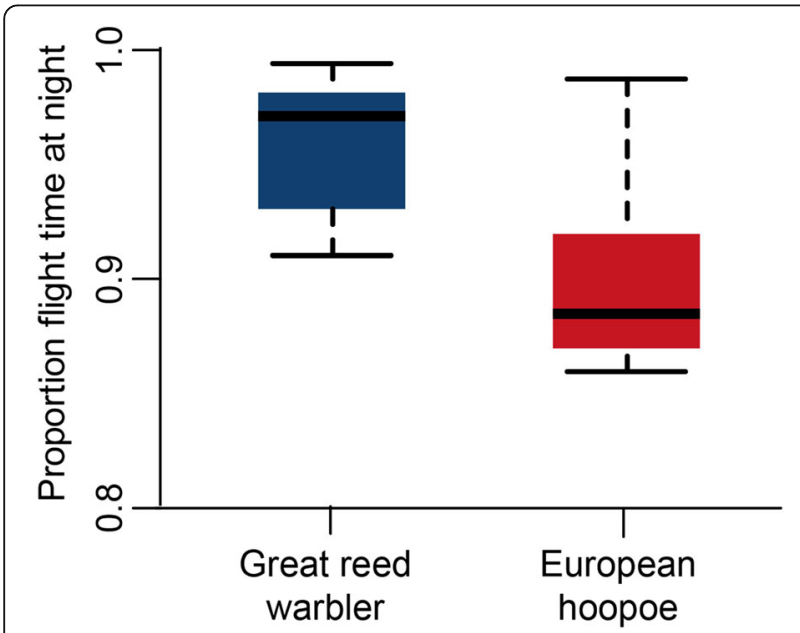

Fig. 4 Distribution of the individual proportion of nocturnal flight activity for eurasian hoopoes (red, $n=5$ ) and great reed warblers (blue, $n=13$ ). Day and night was derived from the tag's light sensor. The plots represent median, $50 \%$ quantile and range initial effect, high climb rates were not related to the time of flight. Climb rates of hoopoes were slightly higher compared to great reed warblers (mean $0.19 \mathrm{~m} / \mathrm{s}$ vs $0.17 \mathrm{~m} / \mathrm{s} ; \mathrm{X}^{2}=3.7, p=0.053$ ). In great reed warblers, the overall rate of change in flight altitude within $30 \mathrm{~min}$ was $159 \mathrm{~m}$ (median, $50 \%$ range: $54-367 \mathrm{~m}$ ) and $194 \mathrm{~m}(55-442 \mathrm{~m})$ in eurasian hoopoes. In great reed warblers the total amount of height changes was $100 \%$ larger during pre- than post-breeding migration and $50 \%$ larger in hoopoes. However, these height changes were closely related to the individual flight durations per migration period (Fig. 7b). These observations indicate that flight altitude was hardly constant over more than a few dozen minutes.

\section{Discussion}

The data from multisensory loggers provide novel and highly detailed insight into the individual timing of flights and the altitudinal pattern for two morphologically different species. Most strikingly, our study shows that variations in behavioural traits, such as length of flight bouts, flight altitude and migratory speed are larger within than between species for the whole annual cycle.

\section{Seasonal pattern in flight activity}

There is no obvious difference in the flight activity between the two species with respect to total flight hours, number of flight bouts for pre- and post-breeding migration, and also the intra-tropical migration performed by the great reed warbler alone [42] does not account for a consistent difference between the species. On average, the intra-tropical migration represented 


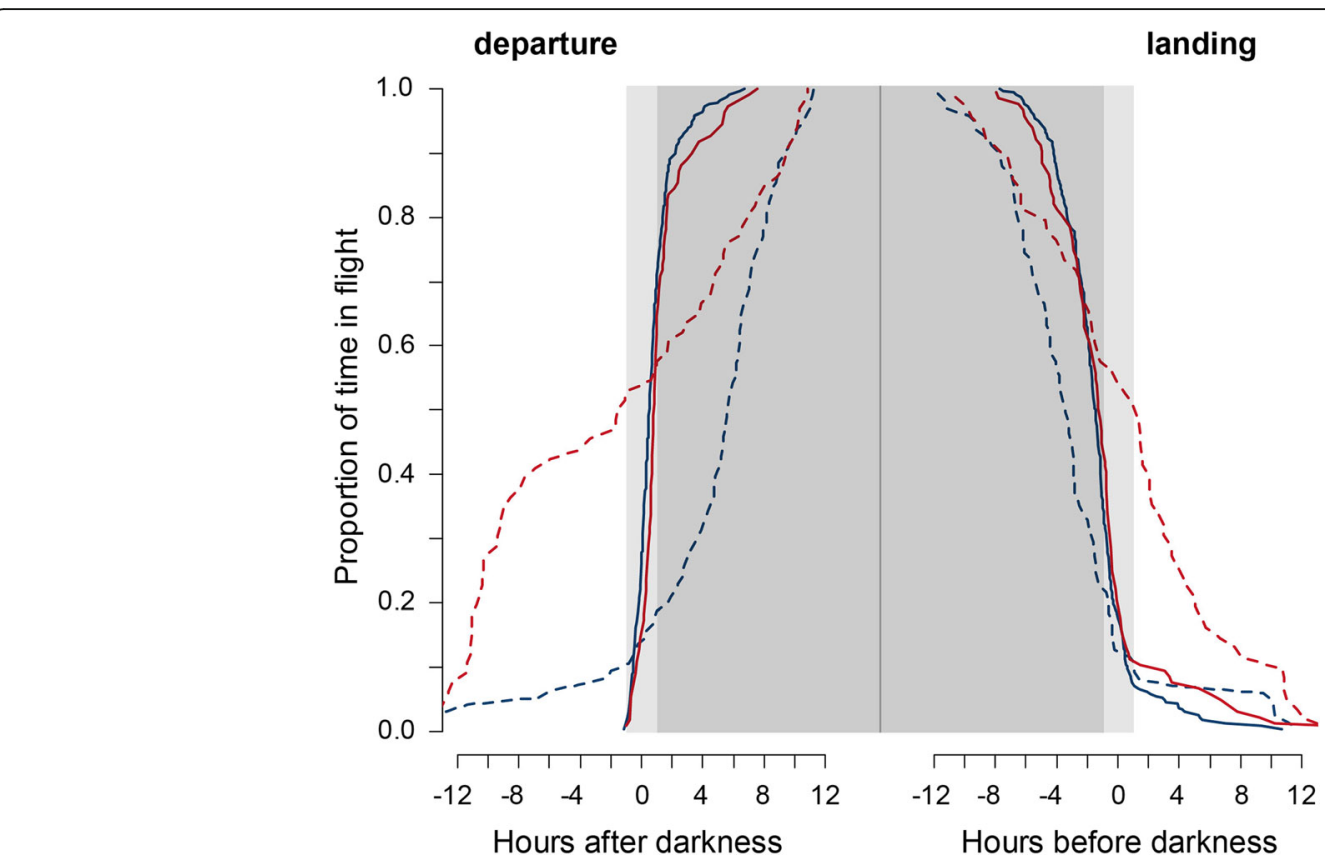

Fig. 5 Timing of departure and landing for eurasian hoopoes (red) and great reed warblers (blue), separated into long (> 4 h, solid lines) and short flight bouts ( $<1 \mathrm{~h}$, dashed lines). Shown are the cumulative frequencies of departures in relation to dusk and landings in relation dawn. $Y=1$ indicates all birds have departed, $Y=0$ all birds have landed. Beginning and end of the night (darkness) are derived from the tag's light sensor. The light shaded area marks an hour before and after darkness, the darker area marks the night

only $10 \%$ of overall flight time and varied considerably between individuals. It is generally assumed that pre-breeding migration is more time constrained than post-breeding migration $[50,51]$. In contrast to this assumption, we did not find a difference in the length of post- and pre-breeding migration in hoopoes, and in great reed warblers post-breeding migration was much shorter and much more synchronized than pre-breeding migration. Most likely, the first non-breeding residence site in sub-Saharan Africa may provide temporarily restricted food resources, because most individuals migrate further after about two months [43]. Ephemeral

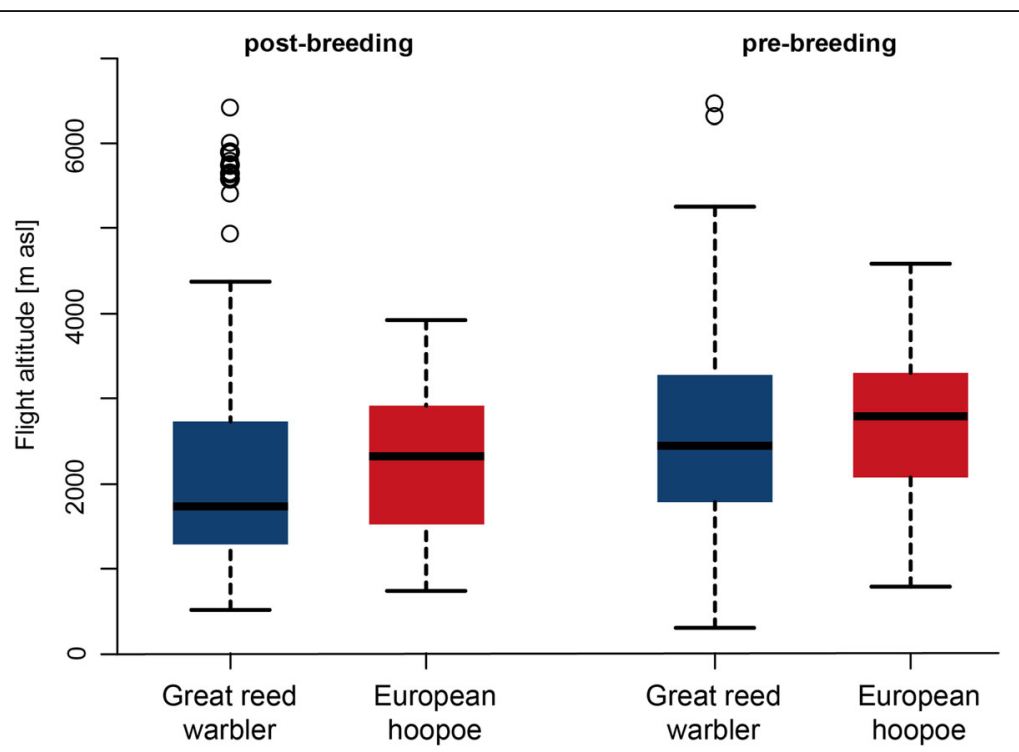

Fig. 6 Distribution of the seasonal maximum individual flight altitudes per flight bout of at least $4 \mathrm{~h}$ for great reed warblers (blue, $n=352$ ) and eurasian hoopoes (red, $n=110$ ) 


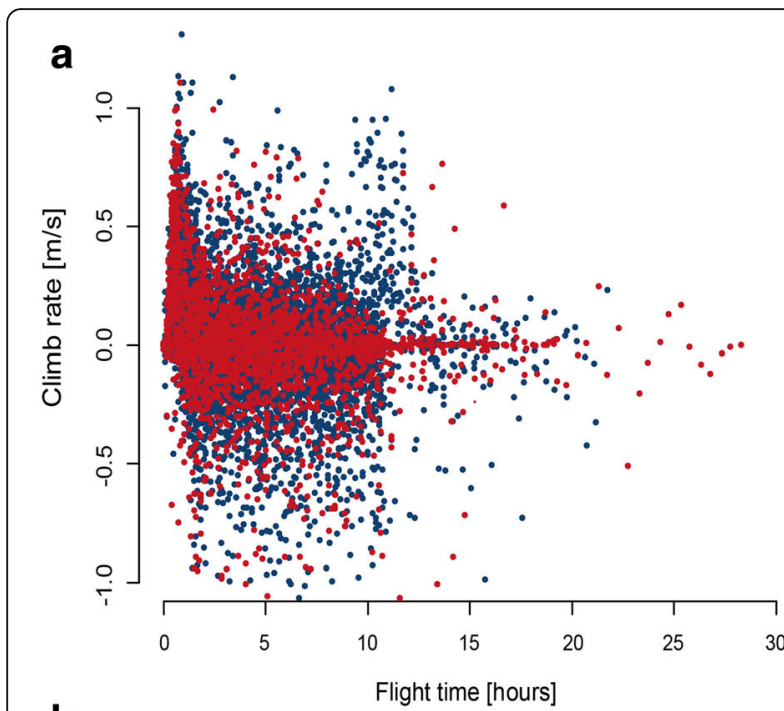

b

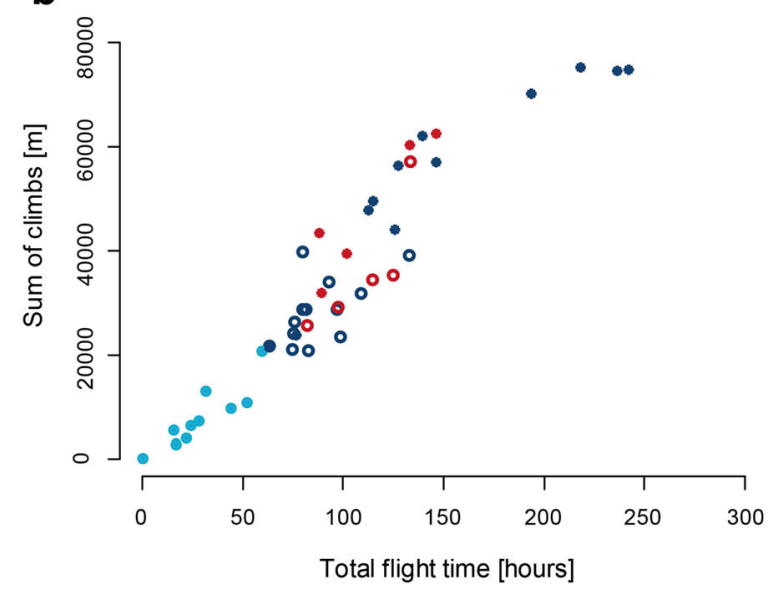

Fig. 7 Climbing behaviour of great reed warblers (blue) and european hoopoes (red): a) rate of climbing and descending per $30 \mathrm{~min}$ flight intervals in relation to the time after departure. A climb rate of $1 \mathrm{~m} / \mathrm{s}$ corresponds to a height change of $1800 \mathrm{~m}$ within $30 \mathrm{~min}$ and a change in air pressure of about $190 \mathrm{hPa}$. The final landing phases (last $30 \mathrm{~min}$ ) are excluded (reed warbler $n=7150$, hoopoes $n=2448$ ). b) sum of climbs for post-breeding (open symbols), intra-tropical (filled light blue) and pre-breeding migration (filled blue/red) in relation to the total individual flight time per migration period

food availability at these sites would increase the need to be there in time, perhaps just after the seasonal rainfalls.

It is unclear why great reed warblers spent considerably more time in flight during the pre-breeding migration, than during both autumn migration and intra-tropical movement. Longer flight times might be caused either by detours or slower ground speeds due to opposing winds. Although pre-breeding migration was more extended than post-breeding migration, due to the additional movements southward during December, one bird returned from its residence area south of the Sahara within one week, flying $74.5 \mathrm{~h}$ during 8 consecutive nights (2-18 h per day). Assuming that flight costs relates to $1 \%$ of the body mass per hour (Hedenström 2010), a bird would be expected to have lost about $50 \%$ (if no refuelling occurred during daytime), which is close to the limit of the range of body mass observed along the migratory flyway [52].

\section{Diurnal flight activity pattern}

For the first time we could quantify the proportion of nocturnal flights in small long distance migrants. The results confirm previous (anecdotal) observations that great reed warblers are predominately nocturnal migrants and clarify the status of eurasian hoopoes as a mainly nocturnal migrant. The regular occurrence of short diurnal flights (Fig. 5), and thus the potential for visual observations during the day, may have led to the ambiguous assessment of the species as a mainly diurnal and occasional nocturnal migrant.

\section{Flight altitude}

Surprisingly, flight altitudes of thousand meters above sea level or more are common in both species, and are not likely indicative of mountain crossings. Indeed, very high altitude flights occur regularly during post- and pre-breeding migration, and are more frequent in great reed warblers than in eurasian hoopoe. This difference may be partly a result of unequal sample sizes. An overview including quantitative radar observations from the Baltic Sea to the Sahara, revealed an upper limit of the $90 \%$ quantile to be between 1400 and $2100 \mathrm{~m}$ a.s.l. [53]. We found an upper limit of more than $3000 \mathrm{~m}$ a.s.l. for both species, which is considerably higher than previously observed flight heights (Additional file 1: Figure S4). Whether this is due to a geographically biased sampling of radar data or due to a different preference of flight altitude by these species, remains an open question. We assume that flights at very high altitude are related to favourable wind conditions, as has been also seen by radar observations [54].

Climbs and descents occur throughout a flight bout, and there was only a slight decrease in climb rates with time in flight. This indicates that flight altitudes are changed throughout a flight bout, either due to crossing mountain ranges and/or to changing wind conditions. Some great reed warblers flying into the day (after 10-12 h of flight) show a considerably increased climb rate leading to very high flight altitudes (Fig. 7a). The overall sum of ascents was considerably larger during pre- than post-breeding migration, which supports the seasonal differences in flight altitudes recorded by radar in the western Sahara [18]. The somewhat higher climb rates recorded in the eurasian hoopoe compared to the great reed warbler confirm the expectations based on their lower wing loadings. The 
overall sum of ascents makes up about $1 \%$ of the total great circle distance covered by an individual bird (see Table 1, Additional file 1: Table S2), and further investigations will be needed to understand the costs and benefits of these vertical movements.

\section{Conclusion}

We could not support our initial hypothesis that eurasian hoopoes with their broader wings and the fickle flight style are less efficient migrants with respect to flight behaviour. Neither flight altitude, the number of flight hours per distance covered nor the lengths of single flight bouts indicated varying flight efficiency between the two species. Our analyses have shown that multi-sensor loggers have the potential to provide insights into many fundamental aspects of individual behaviour in small aerial migrants. Naturally, our analyses are only the tip of the iceberg entailing a range of future analyses. For instance, accuracy in light-based geolocation is heavily affected by shading effects, thus activity patterns can accurately distinguish movement and stationary periods, and air pressure recordings during stop-over periods could be used to narrow down the position of stop-over areas. Furthermore, activity patterns during stop-over or resident periods might provide information on individual habitat use and energy budgets. Combining flight altitudes and locations with environmental/weather data can identify cues for migratory decisions and can significantly help to improve individual movement models. The detailed and long term recordings of data, as presented in this study, are suitable not only for bird migration studies, but also for many other investigations in the field of behavioural research and movement ecology.

\section{Additional file}

Additional file 1: Formula. Calculation of height from pressure recordings. Table S1. Overview of mean flight altitudes per species and season. Table S2. Overview of the sum of ascents per species and migration period. Figure S1. Illustration of recording and data compression of acceleration data. Figure S2. Example of the frequency distribution of the activity recordings (definition see Fig. S1) Figure S3. Great circle distances between seasonal residence areas in relation to flight time. Figure $\mathbf{S} 5$. Standardized residual plot of the generalized linear mixed effect model. (DOCX $185 \mathrm{~kb}$ )

\section{Acknowledgements}

We wish to thank the numerous people who helped us in the field, in Bulgaria and Switzerland. We thank Michael Schaub for organizing the field work in Switzerland.

\section{Funding}

The field work in Bulgaria was supported by the Swiss National Science Foundation (grant number 31003A_138354). The Swiss federal office for environment contributed financial support for the development of the data loggers (UTF-Nr. 254, 332, 363, 400). The publication is report number 63 from The Biological Station Kalimok.

\section{Availability of data and materials}

The datasets used and analysed in this study are available from the correspondig author on reasonable request.

\section{Authors' contributions}

FL analyzed the data and wrote the paper. SB, KD, TE, PZ and SH provided substantial edits on the paper. TE and PZ were responsible for data collection at the Bulgarian site. All authors read and approved the final manuscript.

\section{Ethics approval}

All capture and handling of eurasian hoopoes in Switzerland complied with contemporary laws regulating the treatment of animals in Switzerland and was approved by the appropriate management agencies and ethical committees. All capture and handling of great reed warblers in Bulgaria on was permitted by the Bulgarian Ministry of Environment and Waters (no. 627/30.03.2015)

\section{Consent for publication}

Not applicable.

\section{Competing interests}

The authors declare that they have no competing interests

\section{Publisher's Note}

Springer Nature remains neutral with regard to jurisdictional claims in published maps and institutional affiliations.

\section{Author details}

${ }^{1}$ Swiss Ornithological Institute, Department of Bird Migration, Seerose 1, 6204 Sempach, Switzerland. ${ }^{2}$ Institute of Biodiversity \& Ecosystem Research, Bulgarian Academy of Sciences, Sofia, Bulgaria.

Received: 6 February 2018 Accepted: 26 July 2018

Published online: 02 October 2018

\section{References}

1. O'Connor CM, Norris DR, Crossin GT, Cooke SJ. Biological carryover effects: Linking common concepts and mechanisms in ecology and evolution. Ecosphere. 2014;5:art28. doi:https://doi.org/10.1890/ES13-00388.1

2. Vansteelant W, Shamoun-Baranes J, McLaren J, van Diermen J, Bouten W. Soaring across continents: decision-making of a soaring migrant under changing atmospheric conditions along an entire flyway. J Avian Biol. 2017; https://doi.org/10.1111/jav.01298

3. Wakefield ED, Phillips RA, Matthiopoulos J. Quantifying habitat use and preferences of pelagic seabirds using individual movement data: a review. Mar Ecol Prog Ser. 2009;391:165-82. https://doi.org/10.3354/meps08203.

4. Bouten W, Baaij EW, Shamoun-Baranes J, Camphuysen KCJ. A flexible GPS tracking system for studying bird behaviour at multiple scales. J Ornithol. 2013;154:571-80.

5. Bridge ES, Kelly JF, Contina A, Gabrielson RM, MacCurdy RB, Winkler DW. Advances in tracking small migratory birds: a technical review of light-level geolocation. JField Ornithol. 2013;84:121-37.

6. Bächler E, Hahn S, Schaub M, Arlettaz R, Jenni L, Fox AD, et al. Year-round tracking of small trans-Sahara migrants using light-level geolocators. PLoS One. 2010; https://doi.org/10.1371/journal.pone.0009566

7. Liechti F, Scandolara C, Rubolini D, Ambrosini R, Korner-Nievergelt F, Hahn $\mathrm{S}$, et al. Timing of migration and residence areas during the non-breeding period of barn swallows Hirundo rustica in relation to sex and population. JAvian Biol. 2015;46:254-65.

8. Hahn $S$, Amrhein V, Zehtindijev P, Liechti F. Strong migratory connectivity and seasonally shifting isotopic niches in geographically separated populations of a long-distance migrating songbird. Oecologia. 2013;173: 1217-25.

9. Hobson KA, Kardynal KJ, van Wilgenburg SL, Albrecht G, Salvadori A, Cadman MD, et al. A continent-wide migratory divide in north American breeding barn swallows (Hirundo rustica). PLoS One. 2015;10:e0129340.

10. Cooper NW, Hallworth MT, Marra PP. Light-level geolocation reveals wintering distribution, migration routes, and primary stopover locations of an endangered long-distance migratory songbird. J Avian Biol. 2017:48:20919. https://doi.org/10.1111/jav.01096 
11. Adamik P, Emmenegger T, Briedis M, Gustafsson L, Henshaw I, Krist M, et al. Barrier crossing in small avian migrants: individual tracking reveals prolonged nocturnal flights into the day as a common migratory strategy. Sci Rep. 2016:6:21560. https://doi.org/10.1038/srep21560

12. Hahn S, Emmenegger T, Lisovski S, Amrhein V, Zehtindjiev P, Liechti F. Variable detours in long-distance migration across ecological barriers and their relation to habitat availability at ground. Ecol Evol. 2014;4:4150-60.

13. Stutchbury BJM, Tarof SA, Done T, Gow E, Kramer PM, Tautin J, et al. Tracking long-distance songbird migration by using Geolocators. Science. 2009:323:896. https://doi.org/10.1126/science.1166664 .

14. Lisovski S, Hewson CM, Klaassen RHG, Korner-Nievergelt F, Kristensen MW, Hahn S. Geolocation by light: accuracy and precision affected by environmental factors. Methods Ecol Evol. 2012;3:603-12.

15. Bruderer B, Peter D, Boldt A, Liechti F. Wing-beat characteristics of birds recorded with tracking radar and cine camera. Ibis. 2010;152:272-91.

16. Liechti F, Klaassen M, Bruderer B. Predicting migratory flight altitudes by physiological migration models. Auk. 2000;117:205-14.

17. Schmaljohann H, Bruderer B, Liechti F. Sustained bird flights occur at temperatures far beyond expected limits. Anim.Behav. 2008;76:1133-8

18. Schmaljohann H, Liechti F, Bruderer B. Trans-Sahara migrants select flight altitudes to minimize energy costs rather than water loss. Behav Ecol Sociobiol. 2009;63:1609-19.

19. Liechti F, Schaller $E$. The use of low-level jets by migrating birds. Naturwissenschaften. 1999;86:549-51.

20. Alerstam T. Redwing (Turdus iliacus) migration towards southeast over southern Sweden. Vogelwarte. 1975;28:2-17.

21. Alerstam T, Rosen M, Bäckman J, Ericson PGP, Hellgren O. Flight speeds among bird species: Allometric and phylogenetic effects. PLoS Biol 2007;5: e197. doi:https://doi.org/10.1371/journal.pbio.0050197.

22. Bäckman J, Alerstam T. Orientation scatter of free-flying nocturnal passerine migrants: components and causes. AnimBehav. 2003;65:987-96.

23. Larkin RP, Griffin DR, Torre-Bueno JR, Teal J. Radar observations of bird migration over the western North Atlantic Ocean. BehavEcolSociobiol. 1979; 4:225-64.

24. Diehl RH, Larkin RP. Wingbeat frequency of two Catharus thrushes during nocturnal migration. Auk. 1998;115:591-601.

25. Karlsson H, Nilsson C, Bäckman J, Alerstam T. Nocturnal passerine migrants fly faster in spring than in autumn: a test of the time minimization hypothesis. Anim Behav. 2012;83:87-93. https://doi.org/10.1016/j.anbehav. 2011.10.009

26. Chapman JW, Nilsson C, Lim KS, Bäckman J, Reynolds DR, Alerstam T. Adaptive strategies in nocturnally migrating insects and songbirds: contrasting responses to wind. J Anim Ecol. 2016;85:115-24.

27. Gauthreaux SA. The use of small mobile radars to detect, monitor, and quantify bird movements. Proceedings of the Wildlife Hazards to Aircraft Conference and Training Workshop. 1984:121-31.

28. Åkesson S, Alerstam T, Hedenström A. Flight initiation of nocturnal passerine migrants in relation to celestial orientation conditions at twilight. J.Avian Biol. 1996;27:95-102.

29. Brown JM, Taylor PD. Migratory blackpoll warblers (Setophaga striata) make regional-scale movements that are not oriented toward their migratory goal during fall. Movement Ecology. 2017;5:15. https://doi.org/10.1186/s40462017-0106-0

30. Sapir N, Wikelski M, Avissar R, Nathan R. Timing and flight mode of departure in migrating European bee-eaters in relation to multi-scale meteorological processes. Behav Ecol Sociobiol. 2011;65:1353-65. https:// doi.org/10.1007/s00265-011-1146-x

31. Bowlin MS, Cochran WW, Wikelski MC. Biotelemetry of New World thrushes during migration: physiology, energetics and orientation in the wild. Integr Comp Biol. 2005;45:295-304. https://doi.org/10.1093/icb/45.2.295

32. Meier CM, Karaardıç H, Aymí R, Peev SG, Bächler E, Weber R, et al. What makes alpine swift ascend at twilight?: novel geolocators reveal year-round flight behaviour. Behav Ecol Sociobiol. 2018;72:121. https://doi.org/10.1007/ s00265-017-2438-6

33. del Hoyo J, Elliot A, Sargatal J. Editors. Handbook of the birds of the world Vol. 6 Mousebirds to hornbills. Barcelona: Lynx Ed; 2001.

34. Ed JS, García E. In: Helm C, editor. The birds of the Iberian Peninsula. London; 2015.

35. Bruderer B, Boldt A. Flight characteristics of birds: I. Radar measurements of speeds. Ibis. 2001;143:178-204.
36. Reichlin TS, Schaub M, Menz MHM, Mermod M, Portner P, Arlettaz R, Jenn L. Migration patterns of hoopoe Upupa epops and wryneck Jynx torquilla: an analysis of European ring recoveries. JOrnithol. 2009;150:393-400.

37. van Wijk RE, Schaub M, Bauer S. Dependencies in the timing of activities weaken over the annual cycle in a long-distance migratory bird. Behav Ecol Sociobiol. 2017;71:5. https://doi.org/10.1007/s00265-017-2305-5

38. del Hoyo J, Elliott A, Christie D, Arlott N, Burn H. Old World flycatchers to Old World warblers. Barcelona: Lynx Ed; 2006.

39. Zehtindjiev $P$, llieva M, Westerdahl H, Hansson B, Valkiūnas $G$, Bensch S. Dynamics of parasitemia of malaria parasites in a naturally and experimentally infected migratory songbird, the great reed warbler Acrocephalus arundinaceus. Exp Parasitol. 2008;119:99-110. https:/doi.org/10.1016/j.exppara.2007.12.018

40. Zehtindjiev P. Body condition and fat score in local and passage populations of the great reed warbler (Acrocephalus arundinaceus) during the spring migration in NE Bulgaria. Ring. 2005;27:77. https://doi.org/10. 2478/v10050-008-0025-y

41. van Wijk RE, Bauer S, Schaub M. Repeatability of individual migration routes, wintering sites, and timing in a long-distance migrant bird. Ecol Evol. 2016; https://doi.org/10.1002/ece3.2578.

42. Koleček J, Procházka P, El-Arabany N, Tarka M, Ilieva M, Hahn S, et al. Crosscontinental migratory connectivity and spatiotemporal migratory patterns in the great reed warbler. J Avian Biol. 2016;47:756-67. https://doi.org/10.1111/ jav.00929

43. Koleček J, Hahn S, Emmenegger T, Procházka P. Intra-tropical movements as a beneficial strategy for Palearctic migratory birds. Royal Society Open Science. 2018:5:171675. https://doi.org/10.1098/rsos.171675

44. van Wijk RE, Souchay G, Jenni-Eiermann S, Bauer S, Schaub M. No detectable effects of lightweight geolocators on a Palaearctic-African long-distance migrant. J Ornithol. 2016;157:255-64. https://doi.org/10.1007/s10336-015-1274-6 .

45. Liechti F, Witvliet W, Weber R, Bächler E. First evidence of a 200-day nonstop flight in a bird. Nat Commun. 2013;4:2554. https://doi.org/10.1038/ ncomms3554

46. Stull R. Practical meteorology: an algebra-based survey of atmospheric science. Vancouver: AVP International, University of British Columbia; 2016.

47. Klose B, Klose H. Meteorologie: Eine interdisziplinäre Einführung in die Physik der Atmosphäre. 2nd ed. Berlin: Springer Spektrum; 2015.

48. Lisovski S, Hahn S. GeoLight - processing and analysing light-based geolocator data in R. Methods Ecol Evol. 2012;3:1055-9.

49. R Core Team. R: A language and environment for statistical computing. $R$ Foundation for Statistical Computing, Vienna, Austria. 2014. http://www.Rproject.org/.

50. Kokko H. Competition for early arrival in birds. J Anim Ecol. 1999;68:940-50.

51. Alerstam T, Lindström A. Optimal bird migration: the relative importance of time, energy, and safety. In: Gwinner E, editor. Bird migration: physiology and ecophysiology. Berlin Heidelberg: Springer; 1990. p. 331-51.

52. Yohannes E, Biebach H, Nikolaus G, Pearson DJ. Migration speeds among eleven species of long-distance migrating passerines across Europe, the desert and eastern Africa. J Avian Biol. 2009;40:126-34. https://doi.org/10. 1111/j.1600-048X.2008.04403.x

53. Bruderer B, Peter D, Korner-Nievergelt $F$. Vertical distribution of bird migration between the Baltic Sea and the Sahara. J Ornithol. 2018;41:282. https://doi.org/10.1007/s10336-017-1506-z .

54. Bruderer B, Peter D. Windprofit favouring extreme altitudes of bird migration. OrnitholBeob. 2017;114:73-86.

Ready to submit your research? Choose BMC and benefit from

- fast, convenient online submission

- thorough peer review by experienced researchers in your field

- rapid publication on acceptance

- support for research data, including large and complex data types

- gold Open Access which fosters wider collaboration and increased citations

- maximum visibility for your research: over $100 \mathrm{M}$ website views per year

At $\mathrm{BMC}$, research is always in progress.

Learn more biomedcentral.com/submission 